\title{
Corrigendum: Iguratimod as a New Drug for Rheumatoid Arthritis: Current Landscape
}

\author{
Sisi Xie, Shu Li, Jing Tian and Fen Li \\ Department of Internal Medicine, The 2nd Xiangya Hospital of Central South University, Changsha, China
}

Keywords: iguratimod, rheumatoid arthritis, NF-kappa B, randomized controlled trial, pharmacology

\section{A Corrigendum on}

Iguratimod as a New Drug for Rheumatoid Arthritis: Current Landscape

by Xie S, Li S, Tian J and Li F (2020). Front. Pharmacol. 11:73. doi: 10.3389/fphar.2020.00073

In the original article, there was a mistake in Table 2 as published. The row headers of Table 2 in the article are missing. The corrected Table 2 appears below.

The authors apologize for this error and state that this does not change the scientific conclusions of the article in any way. The original article has been updated.

\section{REFERENCES}

\section{OPEN ACCESS}

Edited and reviewed by: Gerard Bannenberg, GOED, United States

*Correspondence: Fen $\mathrm{Li}$

Lifen0731@csu.edu.cn

Specialty section:

This article was submitted to Inflammation Pharmacology,

a section of the journal

Frontiers in Pharmacology

Received: 23 March 2020 Accepted: 27 March 2020

Published: 08 April 2020

Citation:

Xie S, Li S, Tian J and Li F (2020)

Corrigendum: Iguratimod as a New

Drug for Rheumatoid Arthritis:

Current Landscape.

Front. Pharmacol. 11:488.

doi: 10.3389/fphar.2020.00488
Duan, X. W., Zhang, X. L., Mao, S. Y., Shang, J. J., and Shi, X. D. (2015). Efficacy and safety evaluation of a combination of iguratimod and methotrexate therapy for active rheumatoid arthritis patients: a randomized controlled trial. Clin. Rheumatol. 34 (9), 1513-1519. doi: 10.1007/s10067-015-2999-6

Ebina, K., Miyama, A., Tsuboi, H., Kaneshiro, S., Nishikawa, M., Owaki, H., et al. (2019). The add-on effectiveness and safety of iguratimod in patients with rheumatoid arthritis who showed an inadequate response to tocilizumab. Mod. Rheumatol. 29 (4), 581-588. doi: 10.1080/14397595.2018.1486939

Hara, M., Ishiguro, N., Katayama, K., Kondo, M., Sumida, T., Mimori, T., et al. (2014). Safety and efficacy of combination therapy of iguratimod with methotrexate for patients with active rheumatoid arthritis with an inadequate response to methotrexate: an open-label extension of a randomized, double-blind, placebo-controlled trial. Mod. Rheumatol. 24 (3), 410-418. doi: 10.3109/14397595.2013.843756

Ishiguro, N., Yamamoto, K., Katayama, K., Kondo, M., Sumida, T., Mimori, T., et al. (2013). Concomitant iguratimod therapy in patients with active rheumatoid arthritis despite stable doses of methotrexate: a randomized, double-blind, placebocontrolled trial. Mod. Rheumatol. 23 (3), 430-439. doi: 10.1007/s10165-012-0724-8

Suto, T., Yonemoto, Y., Okamura, K., Sakane, H., Takeuchi, K., Tamura, Y., et al. (2019). The three-year efficacy of iguratimod in clinical daily practice in patients with rheumatoid arthritis. Mod. Rheumatol. 29 (5), 775-781. doi: 10.1080/14397595.2018.1510879

Xia, Z., Lyu, J., Hou, N., Song, L., Li, X., and Liu, H. (2016). Iguratimod in combination with methotrexate in active rheumatoid arthritis: Therapeutic effects. Z. Rheumatol. 75 (8), 882-833. doi: 10.1007/s00393-015-1641-y

Yoshikawa, A., Yoshida, S., Kimura, Y., Tokai, N., Fujiki, Y., Kotani, T., et al. (2018). Add-on iguratimod as a therapeutic strategy to achieve remission in patients with rheumatoid arthritis inadequately responding to biological DMARDs: A retrospective study. Mod. Rheumatol. 28 (2), 227-234. doi: 10.1080/14397595.2017.1336865

Zheng, N., Guo, C., and Wu, R. (2018). Iguratimod is effective in refractory rheumatoid arthritis patients with inadequate response to methotrexate- cyclosporin A-hydroxychloroquine-prednisone. Scandinavian. J. Rheumatol. 47 (5), 422-424. doi: 10.1080/03009742.2017.1376109

Copyright () $2020 \mathrm{Xie}$, Li, Tian and Li. This is an open-access article distributed under the terms of the Creative Commons Attribution License (CC BY). The use, distribution or reproduction in other forums is permitted, provided the original author(s) and the copyright owner(s) are credited and that the original publication in this journal is cited, in accordance with accepted academic practice. No use, distribution or reproduction is permitted which does not comply with these terms. 
TABLE 2 | Characteristics of the clinical trials of iguratimod in combination for RA.

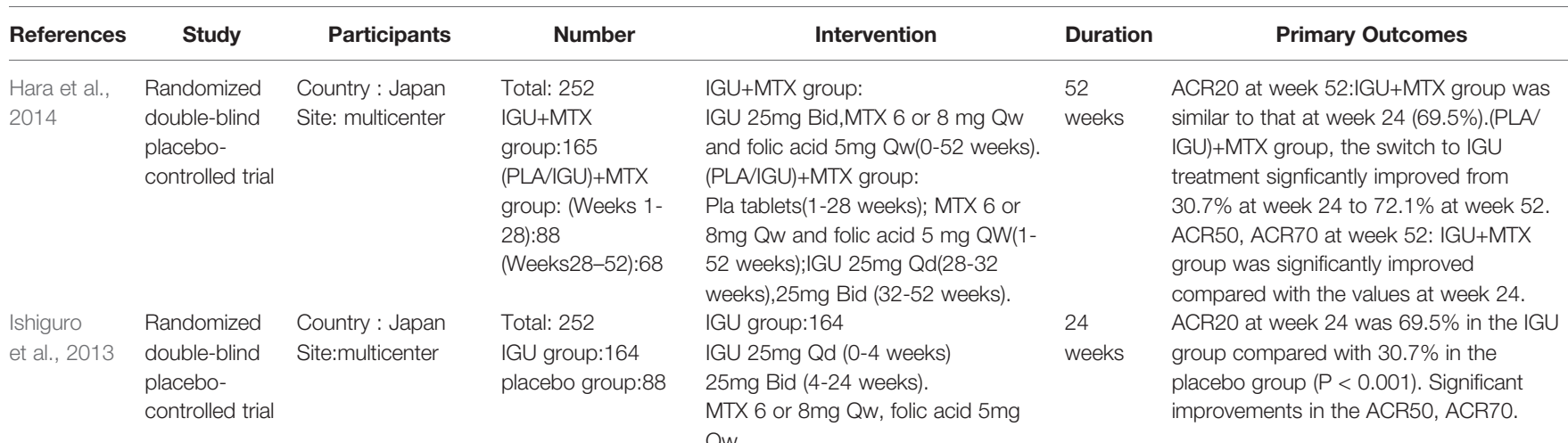

$\begin{array}{lll}\text { Xia et al., } & \text { Prospective } & \text { Country : Japan } \\ 2016 & \text { trial } & \text { Site: Single-center }\end{array}$

Duan et al., Randomized Country : China $2015 \quad$ controlled trial Site : Single-center

Yoshikawa et al., 2018

Retrospective study

Country : Japan Site: Single-center $\begin{array}{ll}\text { Zheng et al., } & \text { Retrospective } \\ 2018 & \text { study }\end{array}$

Country : China Site : Single-center

Ebina et al., Retrospective Country: Japan 2019 study Site: multicenter

Suto et al., Retrospective Country : Japan 2019 study Site:multicenter
Total: 131

MTX+|GU group:44

IGU group:38

MTX group:49

Total: 60

$\mathrm{MTX}+\mathrm{IGU}$

group:30

MTX group:30

Total: 41

patients who

showed an

inadequate

response to

biological DMARDs

Total: 23

patients who

showed an

inadequate

response to MTX-

CsA-HCQ-

prednisone

Total: 31

patients who

showed an

inadequate

response to TCZ

Total: 69

IGU group:28

MTX+IGU:28

bDMARDs+IGU:13 placebo group: MTX 6 or 8mg Qw and folic acid $5 \mathrm{mg}$ Qw, and placebo tablets

IGU group:25mg Bid(0-24 weeks) 24

MTX group:10mg Qw (0-24 weeks) weeks

MTX+IGU group: IGU 25mg Bid (0-

24 weeks).MTX 10mg Qw (0-24

weeks)

MTX+ IGU group: IGU 25mg Bid (0- 24

24 weeks).MTX 10mg Qw (0-4

weeks), 12.5mg Qw (4-24 weeks)

MTX group: 10mg Qw (0-4

weeks),12.5mg Qw (4-24 weeks)

IGU 25mg Qd (0-4 weeks), then

increased to $25 \mathrm{mg}$ Bid based on

the physician's discretion.

MTX:12.5mg Qw

HCQ:0.1mg Bid

CsA:50mg Bid

Prednisone:7.5mg Qd

IGU: 25mg Bid

TCZ 162mg Q2w or 8 mg/kg Qm;

IGU 25 mg Qd,then increased to

$25 \mathrm{mg}$ Bid depending on physician's

decision.

IGU group:IGU 25mg Qd (0-4 weeks), then increased to $25 \mathrm{mg} \mathrm{Bid}$ based on the physician's discretion. MTX+IGU group: MTX was $8.5+$ $3.4 \mathrm{mg} /$ week bDMARDs+IGU group: IFX/ETN/ ADATCZ/ABT/GLM(n=1/4/3/1/2/2) months

\section{weeks}

24 weeks 24 weeks

24 weeks a moderate response, and $51.6 \%$ achieved ACR 20 at 24 weeks

The survival rate of IGU therapy at 3 years was $40.6 \%$. The disease activity was significantly

decreased in the IGU group and MTX plus IGU group compared with the baseline. 